Revista Internacional Educon, Volume I, n. 1, e20011016, set./dez. 2020

ISSN: 2675-6722 | DOI: https:// doi.org/10.47764/e20011016

\title{
Júri Simulado na Educação a Distância: Aplicação da Gamificação no Ensino da Ética e do Direito
}

Mock Trial in Distance Education: Application of Gamification in the Teaching of Ethics and Law

Jurado Simulado en Educación a Distancia: Aplicación de la Gamificación en la Enseñanza de Ética y Derecho

ROBERTA DE SOUSA ALMEIDA ${ }^{1}$, DULCILEIA MARCHESI COSTA², SOLIMARA RAVANI DE SANT'ANNA ${ }^{3}$

${ }^{1}$ Instituto Federal do Espírito Santo

${ }^{2}$ Instituto Federal do Espírito Santo

${ }^{3}$ Instituto Federal do Espírito Santo

\begin{abstract}
RESUMO: A interação entre educador e educando afasta-se, cada vez, mais, das práticas conservadoras de ensino. As metodologias ativas possibilitam o envolvimento e o interesse do aluno, bem como promovem a atitude ativa na aprendiragem, o que é ainda mais desejável na Educação a Distância. A gamificação é um dos recursos didáticos possiveis no ambiente virtual de aprendizagem. No presente estudo, adotou-se uma pesquisa aplicada com abordagem quali-quantitativa, com observação participante, na aplicação de Júri Simulado com alunos do curso Técnico em Multimeios Didáticos, em uma instituição pública de ensino. A prática buscon avaliar o uso da gamificação para aproximar os alunos do conteúdo, desenvolver a argumentação, motivar e tornar a aula virtual mais propicia à interação. A maioria dos alunos (87\%) afirmou motivação no desenvolvimento da atividade. Os resultados apontam que a metodologia utilizada favoreceu o engajamento, a interação e a aprendizagem dos alunos.
\end{abstract}

METODOLOGIA ATIVA DE APRENDIZAGEM. GAMIFICAÇÃO. JÚRI SIMULADO. EDUCAÇÃO A DISTÂNCIA.

\begin{abstract}
$\boldsymbol{A B S T R A C T : ~ T h e ~ i n t e r a c t i o n ~ b e t w e e n ~ e d u c a t o r ~ a n d ~ s t u d e n t ~ i s ~ i n c r e a s i n g l y ~ m o v i n g ~ a w a y ~ f r o m ~ c o n s e r v a t i v e ~}$ teaching practices. Active methodologies enable student involvement and interest, as well as promote an active attitude in learning, which is even more desirable in Distance Education. Gamification is one of the possible didactic resources in the virtual learning environment. In the present study, an applied research with a qualiquantitative approach was adopted, with participant observation, in the application of a Mock. Trial with students of the Technical course in Multimedia Didactics, in a public educational institution. The practice sought to evaluate the use of gamification to bring students closer to the content, develop the argument, motivate and make the virtual classroom more conducive to interaction. The majority of students (87\%) said they were motivated to develop the activity. The results show that the methodology used favoured student engagement, interaction and learning.
\end{abstract}

\section{ACTIVE LEARNING METHODOLOGY. GAMIFICATION. MOCK TRIAL. DISTANCE EDUCATION.}

Os autores cedem à Revista Internacional Educon os direitos de primeira publicação do presente artigo. Aplicam-se os termos de uma licença Creative Commons Atribuição 4.0 Internacional (CC BY 4.0), que permite o uso irrestrito, a distribuição e a reprodução em qualquer meio desde que a publicação original seja corretamente citada. 


\begin{abstract}
RESUMO: La interacción entre educador y alumno se aleja cada vez más de las prácticas de enseñanza conservadoras. Metodologias activas permiten la participación e interés de los estudiantes, asi como también promueven una actitud activa en el aprendizaje, que es aún más deseable en la educación a distancia. Gamificación es uno de los posibles recursos didácticos en el entorno virtual de aprendizaje. Es una investigación aplicada con un enfoque cualitativo-cuantitativo, con observación participante, en la aplicación del Jurado Simulado con estudiantes del Técnico en Didáctica Multimedia, en una escuela pública. La práctica buscó evaluar el uso de la gamificación para acercar a los estudiantes al contenido, desarrollar el argumento, motivar y hacer que el aula virtual sea más propicio para la interacción. La mayoría de los estudiantes (87\%) dijeron que estaban motivados en la actividad. Los resultados muestran que la metodologia utilizada favoreció la participación, interacción y aprendizaje de los estudiantes.

\section{METODOLOGÍA DE APRENDIZAGEM ACTIVO. GAMIFICACIÓN. JURADO SIMULADO. EDUCACIÓN A DISTANCIA.}

\title{
Introdução
}

Os métodos de aprendizagem ativa privilegiam os processos de interação entre educador, educando e seus pares, e vêm apresentando resultados positivos nos processos de ensino-aprendizagem. Para Fonseca (2014, p. 160), a aprendizagem, do ponto de vista da interação aluno-professor para a produção de saberes, é uma atividade que produz a "modificabilidade, um processo de mudança provocado pela mediatização do professor e pela prática intencional e motivacional do aluno".

O uso de metodologias ativas pressupõe o papel ativo por parte dos alunos, já que é uma ação pedagógica que estimula o envolvimento na resolução de problemas condizentes com sua área de estudo, concedendo-lhe a oportunidade de exercitar suas habilidades de análise, investigação e reflexão. (Mitre et al., 2008).

A posição do professor altera-se para mediador da aprendizagem e desenvolve situações que permitem a construção de conhecimento por parte do aluno, além de acompanhá-lo e assessorá-lo constantemente, propor desafios e auxiliá-lo a atribuir significado nessa construção. Neste sentido, a gamificação justifica-se como estratégia para envolvimento do aluno com a aprendizagem e interação com seus pares. Constitui-se em uma forma de criar um ambiente facilitador da aprendizagem (Fardo, 2013), permite que os alunos aprendam a aplicar teorias e conceitos e a buscar soluções para diferentes problemas, distanciando-se da memorização e tornando-os protagonistas do seu processo de ensinoaprendizagem (Souza \& Casa Nova, 2017).

No Role-Play Game (RPG), os alunos se colocam no lugar de personagens e desenvolvem atividades a partir da perspectiva desse papel ou função. O Júri Simulado apresenta as mesmas características, já que os grupos são separados em funções ou papéis e atuam na defesa, na acusação ou no julgamento dos casos concretos. Há a separação clara das atuações dos grupos e o professor atua como mediador, organiza e estrutura as contribuições dos grupos. Ainda, a atividade se desenvolve em um ambiente ficcional, que é a sessão de julgamento.

A atividade de Júri Simulado tem potencial para propiciar aos estudantes a vivência da prática científica, no sentido de debater, posicionar-se e defender ideias. Ainda, favorece o aprofundamento dos conteúdos, o desenvolvimento de habilidades argumentativas e a discussão (Vieira, Melo \& Bernardo, 2014).

A prática pedagógica do Júri Simulado exige que o aluno assuma determinado papel e se coloque diante dos problemas e situações fáticas. Tal abordagem permite com maior facilidade trazer a sala de aula questões que extrapolam a preocupação de ensino de conteúdo, como aquelas estratégicas, de negociação, de relacionamento com colegas de equipe, com adversários, e com autoridades públicas, 
dentre outras (Ghirardi, 2012). O ensino jurídico participativo é um paradigma de ensino que se diferencia do ensino tradicional por colocar o estudante como foco no processo de aprendizagem (Feberbaum \& Klafke, 2020).

Realizou-se um estudo de campo com a observação participante, a partir de um estudo qualiqualitativo, para fins de analisar os impactos do Júri Simulado, com ênfase em aspectos como interação, motivação, fluência, argumentação e cooperação entre alunos e entre alunos e professor, reorientando o processo de ensino-aprendizagem no estudo da ética e do direito. Os alunos participantes da pesquisa foram os do $2^{\circ}$ e $3^{\circ}$ períodos de um curso técnico de uma instituição pública de ensino, no primeiro semestre letivo de 2020.

A implementação desta abordagem metodológica em um curso na modalidade a distância, imerso nas potencialidades das tecnologias digitais de informação e comunicação (TDIC), é uma proposta desafiadora, uma vez que existem estudos escassos que a orientam.

\section{A Gamificação como Metodologia Ativa de Aprendizagem na EaD}

A adoção das metodologias ativas tem sido impulsionada nas últimas décadas pela contraposição às metodologias tradicionais de ensino. $\mathrm{O}$ aluno ultrapassa a atuação passiva, como receptor no processo de ensino aprendizagem e adota uma postura interativa, toma frente do aprendizado, atua de forma ativa, sendo mediado pelo professor. A "relação professor/aluno ou ensino-aprendizagem é mediada pedagogicamente e mediatizada por diversos materiais instrucionais e pela orientação tutorial" (Riano, 1997, p. 20).

O professor como mediador, facilitador e ativador do processo de ensino e aprendizagem tem o papel de "provocar, desafiar, ou ainda promover as condições de construir, refletir, compreender, transformar, sem perder de vista o respeito à autonomia e dignidade" dos alunos (Diesel; Baldez; Martins, 2017, p. 278).

Debald e Golfeto (2016, p. 6) sistematizam que o professor deve:

[...] ser flexível e adaptável em diferentes contextos do exercício da profissão docente; utilizar a criatividade no desenvolvimento das atividades docentes; ter disposição para reaprender a função docente; ser paciente e empático com alunos e colegas; agir interdependentemente; aprimorar a produção do conhecimento para solucionar problemas contemporâneos; fundamentar o processo de aprendizagem em desafios e problemáticas da realidade atual; apropriar-se e ser capaz de desenvolver recursos de tecnologia para as atividades de ensino e de aprendizagem; desenvolver habilidades de preceptoria e orientação dos alunos; e adotar atitudes de abertura à mudança.

Segundo Oliveira (2020), existem mudanças nos modos de ser, agir e se relacionar no processo de ensino e aprendizagem, em que a postura do docente não é mais a do detentor de todo saber, mas sim, de um pesquisador experiente que orienta os alunos em suas descobertas. Desta forma, o foco desse processo é o aluno, que desenvolve uma postura protagonista na sua aprendizagem.

Para Moran, Masetto e Behrens (2013, p. 18), “[...] as metodologias ativas são pontos de partida para avançar para processos de reflexão, de integração cognitiva, de generalização, de reelaboração de novas práticas".

A aprendizagem é mais significativa quando os alunos são motivados intimamente, quando eles acham sentido nas atividades propostas, quando consultados suas motivações profundas, quando se engajam em projetos em que trazem contribuições, quando há diálogo sobre as atividades e a forma de realizá-las (Moran, 2013). 
Na perspectiva da construção do conhecimento, Maturana e Varela entendem que, "se a vida é um processo de conhecimento, os seres vivos constroem esse conhecimento não a partir de uma atitude passiva e sim pela interação" (Maturana \& Varela, 1995, p. 12).

Para Damiani (2008, p. 223), as atividades colaborativas podem criar um ambiente rico em aprendizagens acadêmicas e sociais tanto para estudantes como para professores, assim como proporcionar a estes um maior de grau de satisfação. O trabalho colaborativo possibilita, além disso, o resgate de valores como o compartilhamento e a solidariedade - que se foram perdendo ao longo do caminho trilhado por nossa sociedade, extremamente competitiva e individualista. A partir da interação e colaboração dos indivíduos, ocorre a produção, transformação e mudança na identidade desses indivíduos, tanto em seu conhecimento quanto em suas habilidades práticas.

Bergmann e Sams (2016) afirmam que o ambiente de aprendizagem físico ou virtual se destaca, na atuação do professor como facilitador da interação social, com a eleição da estratégia metodológica que oportunize aos alunos o aprendizado a partir da experiência, da colaboração ou mesmo por meio de instrumentos que mediam a interface entre o sujeito e o conhecimento. As atividades colaborativas, também, promovem nos sujeitos, a partir da troca de experiências e do conhecimento, o desenvolvimento da responsabilidade, no que diz respeito a autoria do produto final (Damiani, 2008).

Existem diferentes práticas possíveis para as metodologias ativas, entre as quais está a Gamificação. Trata-se do uso direcionado de elementos para fins educacionais, como a apresentação de objetivos estruturados, feedbacks, desafios, envolvimento dos alunos, situações de competição e cooperação.

Segundo Moran (2018, p. 20) a gamificação apresenta "estratégias importantes de encantamento e motivação para uma aprendizagem mais rápida e próxima da vida real”, ajudando os estudantes no enfrentamento de desafios, fases, dificuldades, a lidar com fracassos e correr riscos com segurança.

Esse poder motivacional pode ser devido aos mecanismos de incentivo e de envolvimento, por exemplo, uma recompensa, a alegria de jogar e/ou a possibilidade de ganhar (Seixas, Gomes, Filho \& Rodrigues, 2014).

A gamificação justifica-se como metodologia ativa de aprendizagem justamente porque corrobora o entendimento de Moran (2013). Para o autor, as metodologias ativas incitam curiosidade, propõem desafios, engajam o aluno em vivências, propiciam trabalhos em colaboração, desenvolvem a autonomia de educandos nas tomadas de decisões, dá ênfase ao papel protagonista do aluno, valoriza seu envolvimento e sua participação efetiva na construção do processo de aprendizagem.

A aplicação da gamificação como uso de metodologia ativa em uma estratégia na construção de um planejamento de ensino-aprendizagem é potencializado se envolto em práticas pedagógicas atualizadas com o uso das TDIC.

A Educação a Distância (EaD) é uma modalidade educacional que se depara com um desafio para além da integração das tecnologias aos processos educacionais, que é a adoção de metodologias ativas de aprendizagem por parte dos professores, especialmente permeadas pelo uso das TDIC. Desta forma, compreender a EaD é compreender o processo de integração das TDIC nos processos educacionais, refletir sobre sua utilização como prática educacional. Mais que isso, é promover ações educativas diferenciadas, com o uso das tecnologias. Não se trata, apenas, daquilo que Belloni e Bérvot (2009) identificam como mediatização técnica, que é a concepção, a fabricação e o uso pedagógico de materiais multimídia. De forma complementar Bacich (2014) destaca que o professor deve aprender com o uso das tecnologias digitais e não sobre o seu uso.

\subsection{Júri Simulado e o Desenvolvimento da Argumentação e da Interação entre os Alunos}


No Júri Simulado, os alunos são separados em papéis, funções, e passam a desenvolver a atividade sob a perspectiva deles, enquanto competidores, debatedores de argumentos e ideias. Posicionam-se como defensores, acusadores e juízes, que funcionam em casos concretos em sessão de julgamento. Os debatedores competem pelos melhores argumentos, a fim de convencer o juiz. Para Souza e Casa Nova (2017), esta estratégia de ensino aumenta o interesse, a compreensão e a integração do aluno com o conteúdo, bem como a sua participação ativa na construção do conhecimento.

O Júri Simulado funciona como um recurso didático que promove o desenvolvimento das argumentações por parte dos alunos, na medida em que se aprofundam voluntariamente, cooperativamente e motivadamente no conteúdo, na busca por melhores ideias de argumentação. Fragelli (2014, p. 231) identificou que o uso da gamificação acarretou em maior participação dos alunos, interesse, alegria e cognitivamente foi verificado o interesse em alcançar um aprofundamento maior. O que se preza é que os estudantes tenham ação ativa na produção de conhecimento, com impacto positivo no seu aprendizado.

Kolstoe (2000) afirma que a prática aumenta a possibilidade de o aluno compreender o ponto de vista de outras pessoas, na medida em que tem que se colocar no lugar delas uma determinada situação, o que gera dificuldades que precisam ser transpostas, já que precisam agir sob a perspectiva de uma pessoa a respeito da qual eles não necessariamente concordam.

Neste sentido, o Júri Simulado é uma estratégia de ensino e desenvolvimento da argumentação dos alunos, que precisam se posicionar frente ao tema em debate, através de contraposições e contra argumentações.

Quanto às dimensões do Júri Simulado, é relevante apresentar algumas possibilidades, tais como: (a) convencimento do juiz, por meio do desenvolvimento do argumento ético e normativo; disputa entre os grupos opostos, da defesa e da acusação e a troca de recursos argumentativos, nos momentos de réplica e tréplica; (b) a avaliação da performance dos componentes, seja individual ou coletivamente, não necessariamente dependente do resultado obtido no julgamento, mas tão somente pelo percurso da criação do discurso de defesa / acusação / julgamento frente ao conteúdo da ética e do direito; (c) a competição com momento específico para ação de cada componente dos grupos; elementos surpresas com informações e provas apresentadas no decorrer do julgamento, o que demanda conhecimento aprofundado do conteúdo, para refutar ou alegar eventual informação e a recompensa do julgamento favorável aos argumentos do grupo representado, bem como a confirmação de acertos na configuração do caso concreto; (d) a introdução de emoções motivadoras quanto ao desenvolvimento do encadeamento e argumentos para fins de convencimento do julgador; sentimento de progressão; desenvolvimento de relacionamento dentre os componentes dos grupos, que interagem e apoiam os argumentos uns dos outros, de modo a torná-los mais fortes e coerentes.

Parte-se de casos concretos ou temas, que são explorados pelos alunos por meio de argumentos de defesa e acusação, análises e avaliações de fatos com objetividade e correlação com o conteúdo. O uso da gamificação pode favorecer o aprendizado de conteúdos mais complexos, que despertam pouco interesse, engajamento e motivação dos estudantes (Fragelli, 2014).

Os alunos precisam desenvolver as habilidades de argumentação, senso crítico, levantamento de hipóteses e tomada de decisões, improvisação, interação e cooperação. Assim, aspectos como a motivação, a interação, a cooperação e a capacidade argumentativa são desenvolvidas a partir da aplicação do Júri Simulado.

Plantin (2005 apud Stumpf, 2016) frisa que as intervenções argumentativas dos alunos nos debates levam a postura ativa do processo de ensino aprendizagem, possibilitam a identificação de afirmações duvidosas e contraditórias, bem como aprofundam o conteúdo e as teorias. Além disso, o debate proporciona ao aluno desenvolver a argumentação fundamentada, a contra argumentação, a agilidade mental, o confronto intelectual e a autoconfiança. (Moura, Pereira e Souza 2017).

A argumentação é entendida nos dizeres de Cuenca (1995) como um meio comunicativo de relação interpessoal que confronta saberes e opiniões com o objetivo de convencimento do ponto de vista. Ainda, Sanmartí (2003 apud Vieira, Melo e Bernardo, 2014), afirma que a argumentação pressupõe a escolha 
entre opções ou explicações e a análise racional que permita o julgamento mais adequado. Ressalta-se que o aprimoramento da capacidade argumentativa do aluno no Júri Simulado foi mencionado por Brito e Sá (2010), uma vez que denota a necessidade de justificar ou refutar um posicionamento, uma tese, uma ideia.

\section{Caminhos Metodológicos}

Esta pesquisa apresenta a aplicação da gamificação, recurso didático do Júri Simulado, com alunos do $2^{\circ}$ e $3^{\circ}$ anos de um curso técnico a distância no primeiro semestre letivo de 2020 . Os materiais didáticos do Júri Simulado foram disponibilizados na sala de aula virtual da disciplina Legislação e Ética, no ambiente virtual de aprendizagem Moodle 3.1, e a simulação do julgamento ocorreu por meio de webconferência. O Júri teve como principais objetivos a aprendizagem centrada no aluno, com ênfase em aspectos como interação, motivação, fluência, argumentação e cooperação entre alunos e entre alunos e professor, reorientando o processo de ensino-aprendizagem no estudo da ética e do direito.

Neste cenário, o presente estudo tem natureza aplicada e exploratória, com abordagem qualiquantitativa e observação participante quanto aos procedimentos da pesquisa, uma vez que existe o envolvimento e a identificação da pesquisadora com os alunos (Silveira \& Córdova, 2009).

Para amostra, foram convidados 46 alunos, dentre os quais 32 foram participantes. Dentre eles, 65,6\% era do gênero feminino e 34,4\% do gênero masculino. As faixas etárias que prevaleceram foram a de 25 a 30 anos, com 28,1\% e a de 41 a 50 anos, com 28,3\%. Em relação à escolaridade, 37,5\% dos alunos possuía ensino médio completo, $34,4 \%$ graduação, $25 \%$ pós-graduação lato sensu e $6,3 \%$ mestrado ou doutorado.

Este estudo foi desenvolvido contemplando o planejamento, a aplicação da prática pedagógica, a coleta de dados e a análise dos dados.

O planejamento das atividades dos júris perpassou pela indicação de referenciais e materiais de apoio sobre o conteúdo de ética, direito e a educação, para que os estudantes pudessem selecionar e realizar o aprofundamento individual quanto o conteúdo geral necessário para embasar as decisões e os argumentos. Os alunos prepararam-se individualmente, de forma proativa, sendo mediados pela professora e primeira pesquisadora do estudo, e puderam esclarecer dúvidas quanto aos conteúdos em momentos síncronos. No total, foram disponibilizadas 15 horas-aula para os procedimentos didáticos, que culminaram no debate do Júri Simulado.

A aplicação do Júri Simulado ocorreu na disciplina de Legislação e Ética de um curso técnico e teve a participação de 32 alunos. Foram desenvolvidas duas rodadas do Júri Simulado em aulas síncronas realizadas por webconferências.

$\mathrm{Na}$ coleta de dados, além da observação participante e dos apontamentos realizados pelos alunos durante a realização dos júris, foi aplicado um questionário semiestruturado, dividido em dez questões fechadas quanto aos Requisitos de Usabilidade; seis questões fechadas quanto aos Requisitos Pedagógicos e três questões abertas, em que os alunos foram estimulados a apresentar posicionamentos acerca dos problemas, dificuldades, potencialidades e sugestões de melhoria da aplicação do Júri Simulado.

A análise deu-se a partir da organização dos dados transcritos, bem como dos gráficos gerados a partir das questões apresentadas aos alunos, exploração do material e definição das temáticas, relacionando os com objetivo de estudo e articulação dos dados produzidos no referencial teórico estudado.

\subsection{OJúri Simulado: Descrição da Experiência}


O contexto em que o Júri Simulado esteve norteado foi o da ética e do direito no ambiente escolar, com casos concretos que envolviam fatos e comportamentos éticos e normativos do ambiente escolar, da legislação escolar, da educação de menores, da responsabilidade da família em relação aos menores, do menor em conflito com a lei e a educação e do Código de Ética dos Profissionais da Educação.

O material utilizado foi composto pelo material preparatório para fins de subsídios para os alunos formularem suas argumentações, disponibilizado antecipadamente pelas professoras mediadoras, com conteúdos na sala de aula virtual, composto por videoaulas, livros no Moodle, e por slides com a apresentação de casos concretos de condutas sociais e condutas no ambiente escolar, que deveriam ser apreciadas pelos alunos, e resolvidas conforme os regramentos éticos e normativos, durante a realização do Júri Simulado.

Quanto à dinâmica, a sala foi dividida em grupos de cinco ou seis alunos. A partir da divisão, foram sorteados os grupos em: "grupo da defesa", "grupo da acusação" e "grupo da decisão". Os alunos atuaram na argumentação de defesa, acusação ou decisão, independentemente de posicionamento pessoal em relação ao caso concreto apresentado.

Então, os grupos passaram a atuar nos casos concretos, dentro do eixo temático norteador da ética no ambiente educacional, apresentando argumentação moral, ética e normativa, interagindo com os pares e realizando contraponto aos argumentos do grupo contrário. Os alunos deveriam apresentar argumentação suficiente para justificar sua atuação de grupo, independentemente de seu posicionamento pessoal frente ao caso concreto. Foi estimulado a que todos os componentes do grupo se manifestassem, seja por áudio/vídeo, seja utilizando-se do chat, por escrito.

O tempo e ordem de exposição de argumentos foi dividido em: dez minutos iniciais para o grupo da acusação, dez minutos para o grupo de defesa, após, manifestação em cinco minutos para a réplica da acusação e cinco minutos para tréplica da defesa. Depois de exaurido o tempo das manifestações, o grupo decisório apresentava entre os argumentos dos grupos aquele que motivou, bem como a solução do conflito ético/normativo apresentado.

Ao final, foi realizado um apanhado dos argumentos apresentados pelos grupos e correlacionaram aos conteúdos da disciplina, indicando a assertividade da decisão tomada pelo grupo, diante do material disponibilizado na disciplina. Cada aluno pode, então, conferir a relação entre o conteúdo e o caso concreto. O Júri Simulado terminou quando os casos concretos, no total de três, foram decididos e correlacionados aos conteúdos da disciplina.

Após a realização, os alunos participantes foram convidados a responderem, sem identificação, a um questionário específico, em que avaliaram a experiência e os requisitos pedagógicos e de usabilidade, bem como a aceitabilidade do Júri Simulado como recurso didático no aprendizado dos conteúdos propostos de ética e de direito.

A avaliação dos alunos se deu a partir do desempenho demonstrado na argumentação e contra argumentação individual, seja oral ou escrita, na coerência diante do posicionamento do grupo, na compreensão e adequação ao do tema e do material disponibilizado, bem como na postura de interação diante do posicionamento dos demais colegas, em avaliação coletiva.

\section{Resultados e Discussão}

A análise dos resultados possibilitou a reflexão das pesquisadoras e a percepção da contribuição dos casos concretos simulados propostos aos alunos para debates, uma vez que instigou o aprofundamento do conteúdo, o pensamento crítico e argumentativo, a pesquisa e o embasamento teórico dos argumentos.

Os alunos foram bastante receptivos à participação no Júri Simulado. Verificou-se pelos relatos das professoras, que os alunos foram motivados a expandirem seus conhecimentos em busca de 
argumentos possíveis a serem utilizados durante a efetivação da atividade. Todos os discentes envolveram-se na dinâmica, seja na participação por vídeo, áudio, seja na participação por meio do chat, por escrito. O resultado corrobora o entendimento de Moran (2018), quanto a atratividade e percepção dos alunos, a linguagem, os desafios, a cooperação e as recompensas.

Quanto à metodologia adotada, a maior parte, $83,3 \%$, indicou que a disposição de conteúdos facilitou a aprendizagem. Dos respondentes, $87 \%$ dos alunos afirmou motivação na prática do Júri Simulado e $82,4 \%$ deles indicou que levou a maior motivação também para o aprofundamento no conteúdo. Cerca de 89\% afirmou que o Júri Simulado permitiu e incentivou a crescente autonomia e o envolvimento dos alunos. Quanto à ampliação da participação em sala, 36\% afirmou que o Júri Simulado ampliou a participação em aula. Em torno de 95\%, também, afirmou que os temas e casos abordados fizeram referência ao universo cotidiano, em uma perspectiva de formação da cidadania. Aproximadamente $86 \%$ indicou o Júri Simulado como relevante para ampliar a interação e a cooperação entre os alunos. Esses resultados corroboram com os princípios das metodologias ativas apresentados por Diesel, Baldez e Martins (2017) que são: o professor como mediador e ativador do processo de ensino e aprendizagem, o aluno como centro do processo de ensino e da aprendizagem, a autonomia do estudante, a reflexão, a problematização da realidade, o trabalho em equipe, e a inovação.

Outros resultados avolumam a percepção das pesquisadoras quanto ao estudo, já que o Júri Simulado mostrou-se atrativo e envolvente para mais de $86 \%$ dos alunos. A maioria dos alunos, 94.4\%, considerou que o Júri Simulado promoveu a criatividade, com a possibilidade de vários caminhos, respostas, soluções. Quanto à resistência ao método, 17\% indicou a necessidade de maior tempo para a preparação dos argumentos e manifestação na sessão. Hamari, Koivisto e Sarsa (2014) também identificaram resultados positivos no uso da gamificação para fins educacionais, com o aumento da motivação, do engajamento e da satisfação dos estudantes, bem como um melhor resultado da aprendizagem.

A avaliação apresentada pelos alunos registrou relatos e maior motivação e interação dos alunos e o interesse pelo aprofundamento do conteúdo, tal como se pode depreender dos trechos abaixo:

Relato 1 - Aula interessante que nos faz aprender de uma forma mais divertida.

Relato 2 - Embora tenha sido interessante, precisaria de mais tempo para as articulações do grupo.

Relato 3 - Através da capacidade crítica a atividade propôs o desenvolvimento de argumentos e análise de seus valores de moral e ética.

Relato 4- A oportunidade de pensar nos "dois lados da moeda", pensar criticamente, respeitar o posicionamento do outro, entre outras coisas.

Relato 5 - Foi muito interessante pois permitiu aprender de forma efetiva através de uma brincadeira. Relato 6 - Proporcionou interação com os demais participantes.

Relato 7 - Muito bom, deu pra entender de forma mais lúdica conceitos da Ética e do Direito que são um pouco complicados de entender.

Relato 8 - Assuntos que acontecem na vida real, sendo aproveitados para melhor assimilação do tema e maior participação do aluno.

Relato 9 - Bom para o desenvolvimento de argumentações dentro do contexto em que está imerso e tem que atuar mesmo que imposto às vezes. Permite também achar soluções.

Relato 10 - Exercício da argumentação, interação entre colegas, desenvolvimento de visão global de situações.

Relato 11 - Discutimos questões complexas a partir dos casos propostos e isso possibilita reflexões e argumentos mais aprofundados.

As observações das pesquisadoras, bem como o resultado das respostas dos alunos, corroboram os entendimentos reiterados da literatura, já apresentados em Souza e Casa Nova (2017); Hamari et al. (2014); Ghirardi (2012); Damiani (2008); Seixas et al. (2014).

Relevante apontar que durante a realização do Júri Simulado, os alunos estavam bastante engajados no processo, inclusive adequando a linguagem formal dos tribunais ao papel desempenhado de 
advogados e juízes. Os alunos envolviam-se na argumentação, normas aplicáveis, provas e pontos que desfavoreciam o grupo contrário. As análises deram conta de que o Júri Simulado possibilitou a produção de argumentos e contra argumentos diversificados.

Tanto os argumentos da defesa, quanto os argumentos da acusação e os apresentados pelos juízes como fundamentos das decisões foram apresentando-se cada vez mais complexos, na medida em que a atividade gamificada se desenvolvia, justamente provocado pela contraposição de ideias e argumentos dos grupos. Ainda, provas apresentadas e fatos identificados durante a sessão de julgamento exigiam dos alunos a criticidade, o pensamento lógico e o raciocínio rápido, sempre ampliando o senso de cooperação entre os componentes dos grupos.

A alternância de papéis durante as sessões de julgamento culminou no desenvolvimento de um apanhado argumentativo complexo (Platin, 2005 apud Stumpf, 2016), com nítida qualidade da literatura de apoio, capacidade de argumentação, agilidade mental (Moura et al., 2017), convencimento do ponto de vista (Cuenca, 1995), bem como possibilitou o ver na perspectiva do outro (Kolstoe, 2000) e a escolha entre opções ou explicações e a análise racional que permita o julgamento mais adequado (Sanmartí, 2003 apud Vieira, Melo \& Bernardo, 2014), o que encontra suporte teórico no referencial estudado.

A percepção também está apoiada em Kolstoe (2000),que afirma que entre as características do modelo de ensino estão a avaliação e crítica de conhecimento e opiniões e o estabelecimento de uma conclusão consensual.

O Júri demonstrou-se um recurso didático propício ao desenvolvimento de argumentações e promoção do aprendizado dos estudantes, por meio da motivação e interação, o que reforça o resultado atingido por Fragelli (2014).

\section{Considerações finais}

A presente pesquisa buscou investigar as potencialidades e peculiaridades do recurso pedagógico, a partir da gamificação, utilizando, para isso, o Júri Simulado. Para tanto, o recurso didático foi aplicado em duas turmas do $2^{\circ}$ e $3^{\circ}$ períodos de um curso técnico de uma instituição pública de ensino, no primeiro semestre letivo de 2020 .

Destaca-se que a metodologia ativa de aprendizagem amplia o engajamento e a motivação dos alunos e o uso de atividades gamificadas é uma estratégia interessante para o processo de ensinoaprendizagem e favorece o aprendizado de conteúdos mais complexos ou de pouco interesse entre os estudantes. Para Moran (2015) e Damiani (2008), as práticas colaborativas e individuais, de competição e colaboração, de estratégia, com etapas e habilidades bem definidas se tornam cada vez mais presentes nas diversas áreas de conhecimento e níveis de ensino.

Diante do objetivo de formar alunos ativos e criativos, a exposição tradicional de conteúdos deve deixar de ocupar o centro das atividades em sala de aula, em favor dos métodos de ensino participativos. O ensino participativo é ferramenta hábil para o êxito no processo de ensino pois demanda do aluno que se desenvolva em diversos aspectos, além daquele de mero assimilador de conteúdos para memorização. A prática pedagógica do Júri Simulado tende a ser eficaz no ensino de disciplinas jurídicas (Ghirardi, 2012).

A partir da efetivação do recurso didático baseado no Júri Simulado, previamente estruturado, observando-se a separação clara das atuações dos grupos e do professor como mediador, procurou-se evidenciar as potencialidades e desafios que há na prática efetiva da aprendizagem proposta pela metodologia ativa, a partir do uso da gamificação, com auxílio das TDIC. Além disso, a partir da efetiva mediação, pelas professoras, gerou reflexões sobre casos concretos e uma relação direta de teoria e realidade, oportunizando a aprendizagem. 
O recurso pedagógico, aplicado no contexto da $\mathrm{EaD}$, demonstrou que é possível adaptar os arranjos didáticos, a partir do contexto de gamificação, com as TDIC, a fim de otimizar o distanciamento físico, característico dessa modalidade de ensino. Para Moran (2012) a educação a distância pode ser feita nos mesmos níveis que o ensino regular.

Alcançando o objetivo proposto, identificou-se a partir da prática pedagógica as seguintes potencialidades: desenvolvimento da habilidade de argumentação e fluência; favorecimento da construção de um conhecimento crítico coletivo; favorecimento da interação entre os pares; favorecimento da cooperação; favorecimento motivação dos alunos; protagonismo discente. Desta maneira, em concordância com Moran (2007), afirma-se que um dos grandes desafios para o educador é ajudar a tornar a informação significativa, a escolher as informações importantes entre tantas possibilidades.

Desta forma, conclui-se que os objetivos educacionais do Júri Simulado foram alcançados, tendo como base a análise dos resultados do questionário, os relatos dos alunos, a atuação dos alunos durante as rodadas e o acompanhamento das professoras no desenvolvimento de todas as etapas de aplicação deste recurso metodológico que envolveu a gamificação com auxílio das TDIC.

Da análise, foi possível uma correlação positiva entre a aplicação da gamificação como estratégias de metodologia ativa da aprendizagem e a obtenção de resultados de maior interação, motivação, fluência e cooperação entre os alunos. Com grande destaque, também, pode-se observar o desenvolvimento da habilidade de argumentação dos alunos e a construção de um conhecimento crítico coletivo. O ensino jurídico deve ter o aluno como protagonista e participante ativo do processo de ensino e aprendizagem (Guirardi \& Oliveira, 2016).

Em relação aos desafios da aplicação do Júri, $17 \%$ dos alunos demonstrou resistência ao método, indicando como motivo principal a necessidade de maior tempo para a preparação dos argumentos e manifestação na sessão; outros alunos consideraram que precisariam de mais tempo para as articulações do grupo.

Na perspectiva de futuras aplicações da gamificação, as rodadas de simulação de julgamento podem ser realizadas também presencialmente, quando um curso for a distância com encontros presenciais, apesar de não ter havido prejuízo na realização por webconferência.

\section{Agradecimentos}

Agradecemos o apoio da Diretoria do Centro de Referência em Formação e em Educação a Distância (Cefor) do Instituto Federal do Espírito Santo.

\section{Referências}

Bacich, L. (2018). Formação continuada de professores para o uso de Metodologias Ativas. In: Bacich, L. e Moran, J. Metodologias ativas para uma educação inovadora: uma abordagem teórico-prática. [Minha Biblioteca]. Retirado de https://integrada.minhabiblioteca.com.br/\#/books/9788584291168/. Acesso em: 24 jul. 2020.

Belloni, M. L.; Bévort, E. (2009). Mídia-educação: conceitos, história e perspectivas. Revista Educação e Sociedade, Campinas, v. 30, n. 109, p. 1081-1102, set./dez. Disponível em: http://www.scielo.br/pdf/es/v30n109/ v30n109a08.pdf. Acesso em 18 jun 2020. 
Bergmann, J.; Sams, A. (2016). Sala de aula invertida: uma metodologia ativa de aprendizagem. (Tradução Afonso Celso da Cunha Serra). $1^{\mathrm{a}}$ ed. Rio de Janeiro: LTC, 104 p.

Brito, J.Q. e Sá, L.P. (2010). Estratégias promotoras da argumentação sobre questões sócio-científicas com alunos do Ensino Médio. Revista Electrónica de Enseñanza de las Ciencias, v. 9, n. 3, p. 505-529.

Cuenca, M. J. (1995). Mecanismos lingüísticos y discursivos de la argumentación. Comunicación, lenguaje y educación, v. 7 , n. 2, p. 23-40.

Damiani, M. F. (2008) Entendendo o trabalho colaborativo em educação e revelando seus benefícios. Disponível em www.scielo.br/pdf/er/n31/n31a13.pdf . 2008. Acesso em: 25 jul. 2020.

Debald, B.S.; Golfeto, N. V. (2016). Protagonismo Estudantil e Metodologias Ativas de Aprendizagem em Tempos de Transformação na Educação Superior. Pleiade, 10(20): 05-11, Jul./Dez.. Disponível em: https://pleiade.uniamerica.br/index.php/pleiade/issue/view/46. Acesso em 26 mar. 2020.

Diesel, A.; Baldez, A. L. S.; Martins, S. N. (2017). Os princípios das metodologias ativas de ensino: uma abordagem teórica. Revista Thema. v. 14, n. 1, p. 268-288. Disponível em:<http://revistathema.ifsul.edu.br/index.php/thema/article/view/404>. Acesso em: 29 jul. 2020.

Fardo, L. M. (2013). A gamificação aplicada em ambientes de aprendizagem. Revista Novas Tecnologias em Educação, Porto Alegre, v. 11, n. 1, p.1-9. Disponível em: < http://www.seer.ufrgs.br/renote/article/view/41629>. Acesso em: 25 jun 2020.

Fonseca, V. (2014). Cognição, Neuropsicologia e Aprendizagem. 6a ed. Editora Vozes, Petrópolis, Rio de Janeiro, 183 p.

Feferbaum, M; Klafke, G. F (2020). Metodologias ativas em direito: guia prático para o ensino jurídico participativo e inovador. São Paulo: Atlas.

Fragelli, T. B O. (2017). Gamificação como um processo de mudança no estilo de ensino aprendizagem no ensino superior: um relato de experiência. Rev. Inter. Educ. Sup.Campinas, SP. v.4, n.1, p.221-233. jan./abr.

Ghirardi, J.G. (2012) O instante do encontro: questões fundamentais para o ensino jurídico. São Paulo: Fundação Getulio Vargas.

Ghirardi, J.G; Oliveira, J.F. (2016). Caminhos da superação da aula jurídica tradicional. Revista Brasileira de Estudos Políticos | Belo Horizonte | n. 113 | pp. 379-404 | jul./dez. Disponível em $:<$ http://bibliotecadigital.fgv.br/dspace/bitstream/handle/10438/10303/O\%20instante\%20do\%20en contro.pdf?sequence $=1>$. Acesso em 03 de ago de 2020 .

Hamari, J., KoivistoJ., \& Sarsa, H. (2014) "Does gamification work? A Literature Review of Empirical Studies on Gamification," 47th Hawaii International Conference on System Sciences, Waikoloa, HI, 2014, pp. 3025-3034, doi: 10.1109/HICSS.2014.377.

Kolstoe, S. D. (2000). Consensus projects: teaching science for citizenship. International Journal of Science Education. Disponível em <https://www.tandfonline.com/doi/pdf/10.1080/095006900289714?needAccess=true $>$. Acesso em 02 de ago de 2020. 
Maturana, H., \& Varela, F. (1995). A árvore do conhecimento: as bases biológicas do entendimento humano. São Paulo: Editorial Psy II.

Mitre, S. M., Batista, R. S., Mendonça, J. M.G, Pinto, N. M. M., Meirelles, C. A. B, Porto, C. P, Moreira, T., \& Hoffmann, L. M. A. (2008). Metodologias ativas de ensino-aprendizagem na formação profissional em saúde: debates atuais. Ciência \& Saúde Coletiva, Rio de Janeiro, v. 13, n. 2, dez. Disponível em: $<$ http://www.scielosp.org/scielo.php?pid=S141381232008000900018\&script=sci_abstract\&tlng=es >. Acesso em 20 jul 2020.

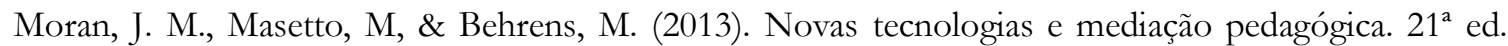
Campinas: Papirus.

Moran, J. M. (2007). A Educação que desejamos: Novos desafios e como chegar lá. Campinas, SP: Papirus.

Moran, J. M. (2012). O que é educação a distância. Disponível em: http://www2.eca.usp.br/moran/wpcontent/uploads/2013/12/dist.pdf. Acesso em 06 ago 2020.

Moran, J. M. (2015). Mudando a educação com metodologias ativas. In Convergências Midiáticas, Educação e Cidadania: aproximações jovens. Coleção Mídias Contemporâneas. Disponível em http://www2.eca.usp.br/moran/wpcontent/uploads/2013/12/mudando_moran.pdf. Acesso em: 2 ago. 2020.

Moran, J. M (2018). Metodologias para uma aprendizagem mais profunda. In: Bacich, L. e Moran, J.. Metodologias ativas para uma educação inovadora: uma abordagem teórico-prática. [Minha Biblioteca]. Retirado de https://integrada.minhabiblioteca.com.br/\#/books/9788584291168/. Acesso em: 29 jul. 2020.

Moran, J. M (2015). Coleção Mídias Contemporâneas. Convergências midiáticas, educação e cidadania: aproximações jovens. Vol. II] Carlos Alberto de Souza e Ofelia Elisa Torres Morales (orgs.). PG: Foca Foto-PROEX/UEPG, 2015. Acesso em: 29 jul. 2020.

Moura, M. F., Pereira, N. A., \& Souza, S. T. (2017). Debate: uma técnica de ensino voltada a pluralidade de pontos de vista. In: Revolucionando a sala de aula: como envolver o estudante aplicando as técnicas de metodologias ativas de aprendizagem. São Paulo: Atlas. cap. 5, p. 51-62.

Oliveira, Z. M. R. (2010). O currículo na educação infantil: o que propõem as novas diretrizes nacionais? Ministério da Educação. Orientações curriculares nacionais para educação infantil. Brasília: MEC/SEF.

Oliveira. S. (2020). Modos de ser estudante as pedagogias ativas: autonomia e aprendizagem na experiência do indivíduo livre. In: Debald, B. Metodologias Ativas no Ensino Superior: O Protagonismo do Aluno - Série Desafios da Educação. Grupo A.

Riano, M. B. R. (1997). La evaluación em educación a distancia. In Revista Brasileira de Educação a Distância. Rio de Janeiro. Instituto de Pesquias Avançadas. Ano IV, Nº 20, p 19-35.

Silveira, D. T., \& Córdova, F. P. (2009). A pesquisa científica. In: Gerhardt, T. E.; Silveira, D. T. (Org.). Métodos de pesquisa. Disponível em: $<$ http://www.ufrgs.br/cursopgdr/downloadsSerie/derad005.pdf>. Acesso em: 4 mar. 2020. 
Seixas, L. D., Gomes, A. S., Filho, I. J., \& Rodrigues, R. L. (2014). Gamificação como Estratégia no Engajamento de Estudantes do Ensino Fundamental. Anais do XXV Simpósio Brasileiro de Informática na Educação (SBIE 2014).

Souza, L. N., \& Casa Nova, S. P C. (2017). O role-play (jogo de papeis) aplicado no ensino e aprendizagem. In: Leal, E. A., Miranda, G. J., Casa Nova, S. P. D. C. (ORGS.). Revolucionando a sala de aula: como envolver o estudante aplicando técnicas de metodologias ativas de aprendizagem. São Paulo: Atlas.

Stumpf, A. (2016). Júri Simulado: o uso da argumentação na discussão de questões sociocientíficas envolvendo radioatividade. Experiências em Ensino de Ciências V.11, No. 2. Disponível em < https://if.ufmt.br/eenci/artigos/Artigo_ID317/v11_n2_a2016.pdf>. Acesso em 23 de jun. 2020.

Vieira, R. D.; Melo, V. F., \& Bernardo, J. R. R. (2014). O júri simulado como recurso didático para promover argumentações na formação de professores de física: o problema do 'gato'. Ensaio: Pesquisa em Educação em Ciências (Online)., v.16, p.203 - 226.

\section{Sobre os Autores}

\section{ROBERTA DE SOUSA ALMEIDA}

(D) ORCID: https://orcid.org/0000-0001-7992-1184

Doutoranda do Programa de Pós-Graduação em Cognição e Linguagem da Universidade Estadual do Norte Fluminense Darcy Ribeiro (Uenf). Mestre em Administração. Especialista em Direito do Trabalho e Processo do Trabalho e Especialista em Estudos Avançados da Comunicação. Graduada em Direito e em Comunicação Social - Jornalismo. Advogada e Professora do Ensino Básico, Técnico e Tecnológico do Ifes, com atuação nos cursos de Pós-graduação Aperfeiçoamento em Formação Docente para Educação a Distância, Pós-graduação Aperfeiçoamento em Educação e Ambiente, Pós-graduação Aperfeiçoamento em Formação Docente para Educação a Distância, Pós-graduação Aperfeiçoamento em Tecnologias Digitais Aplicadas à Educação e no curso Técnico em Multimeios Didáticos. Experiência e áreas de interesse em Educação a Distância, Tecnologias Educacionais, Metodologias Ativas, Comunicação, Administração de Pessoas, Legislação da Administração Pública, Legislação Ambiental, Legislação Educacional.

E-mail: roberta.almeida@ifes.edu.br

\section{DULCILEIA MARCHESI COSTA}

(D) ORCID: https://orcid.org/0000-0003-1102-2072

Doutoranda do Programa de Pós-Graduação em Cognição e Linguagem da Universidade Estadual do Norte Fluminense Darcy Ribeiro (Uenf). Mestre em Biologia Animal pela Universidade Federal do Espírito Santo e graduação em Ciências Biológicas pela Universidade Federal do Espírito Santo. Atualmente Coordenadora da Pós-graduação Aperfeiçoamento em Formação Docente para Educação a Distância do Centro de Referência em Formação e em Educação a Distância do Instituto Federal do Espírito Santo (Ifes), e Professora do Ensino Básico, Técnico e Tecnológico do Ifes, com atuação nos cursos de Pós-graduação Aperfeiçoamento em Formação Docente para Educação a Distância, Pósgraduação Aperfeiçoamento em Educação Especial Inclusiva, Pós-graduação Aperfeiçoamento em Tecnologias Digitais Aplicadas à Educação, e no curso Técnico em Multimeios Didáticos. Experiência 
nas áreas de Educação a Distância, Tecnologias Educacionais, Metodologias Ativas, Gestão Ambiental, Criação e Manejo de Unidades de Conservação, e Zoologia de Invertebrados.

E-mail: dulcileia.marchesi@ifes.edu.br

\section{SOLIMARA RAVANI DE SANT'ANNA}

(D) ORCID: https://orcid.org/0000-0002-9250-1819

Doutoranda do Programa de Pós-Graduação em Cognição e Linguagem da Universidade Estadual do Norte Fluminense Darcy Ribeiro (Uenf). Atualmente atua como Coordenadora Adjunta da UAB do Cefor/Ifes. Mestre em Educação em Ciências e Matemática (Educimat) pelo Ifes. Especialização (lato sensu) em Internet e Multimídia pela UFES e Graduação em Tecnologia em Processamento de Dados pela Fundação de Assistência e Educação (FAESA). Professora efetiva do Instituto Federal do Espírito Santo (Ifes), desde 2002. Atua na educação a distância (EaD) do Ifes assumindo diversos papéis (Professora, Tutora e Coordenadora de cursos FIC). Atuou como Coordenadora da Formação continuada dos profissionais que atuam na UAB do Ifes no período de 2010 a 2014. Como Coordenadora de Extensão do Ifes no período de 2016 a 2017 e como Coordenadora UAB do Ifes no período de 2018 a 2019. Publicou em parceria o livro Lógica de Programação e Automação. Áreas de interesse: Formação de Professores, Tecnologias Educacionais, Metodologias Ativas de Aprendizagem, Educação a Distância. E-mail:solimara@ifes.edu.br

Submetido: 11 ago. 2020

Aceito: 21 Set. 2020 